\title{
Destecer os 60 anos de Formação econômica do Brasil
}

\author{
[ Unweave the 60 years of "Formação econômica do Brasil"
}

\section{Gustavo Louis Henrique Pinto}

SAES, Alexandre Macchione; BARBOSA, Alexandre de Freitas (org.). Celso Furtado e os 60 anos de Formação econômica do Brasil. São Paulo: Editora Sesc/Publicações BBM, 2021.

RESUMO - Formação econômica do Brasil completou 60 anos de publicação em 20I9, e Celso Furtado é uma vez mais empunhado na reflexão sobre a história e a economia do Brasil, ressignificando os horizontes possíveis de interpretação desse clássico, as influências deixadas (o legado), as críticas historiográficas e econômicas, bem como o seu lugar no pensamento político, social e econômico brasileiro. Celso Furtado e os 60 anos de Formação econômica do Brasil (202I), livro objeto desta resenha, organizado por Alexandre Macchione Saes e Alexandre de Freitas Barbosa, traz I6 análises, em diferentes perspectivas, reforçando a necessidade e a atualidade de se voltar à obra e ao pensamento de Furtado. • PALAVRAS-CHAVE • Formação econômica do Brasil; Celso Furtado; 60 anos. .

\begin{abstract}
The book "Formação econômica do Brasil" completed 60 years of publication in 20I9, and Celso Furtado is once again engaged in reflecting on the history and economy of Brazil, re-signifying the possible horizons of interpretation of this classic, the influences left (the legacy), historiographical and economic criticisms, as well as its place in Brazilian political, social and economic thought. "Celso Furtado e os 60 anos de 'Formação econômica do Brasil'” (202I), book which is object of this review, organized by Alexandre Macchione Saes e Alexandre de Freitas Barbosa, brings I6 analyses, in different perspectives, reinforcing the need and the current moment to turn back the attention to Furtado's work and thinking. . KEYWORDS · Formação econômica do Brasil; Celso Furtado; 6o years.
\end{abstract}

Recebido em I5 de janeiro de $202 \mathrm{I}$

Aprovado em 8 de fevereiro de $202 I$

PINTO, Gustavo Louis Henrique. Destecer os 60 anos de Formação econômica do Brasil. Revista do Instituto de Estudos Brasileiros, Brasil, n. 78, p. 3I5-32I, abr. 202I.

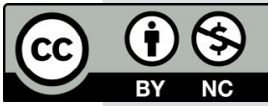

DOI: https://doi.org/Io.II606/issn.23I6-90IX.vIi78p3I5-32I

I Instituto Federal de Educação, Ciência e Tecnologia de Goiás (IFG, Uruaçu, GO, Brasil). 
Formação econômica do Brasil tem a dimensão das análises de interpretação do Brasil que constituiu uma epistemologia, na direção apontada por Fonseca no artigo "Celso Furtado e o estruturalismo como método", como um conhecimento de profundo impacto sobre as ciências sociais e a economia principalmente (e não exclusivamente nessas áreas do conhecimento), que carrega um método específico, ao mesmo tempo que é possuidora de força para a ação política, com finalidades para o presente de I959, explorando um instrumento de análise histórica, em que as dinâmicas (econômicas e das estruturas de poder) possibilitam orientar mudanças estruturais. Rememorar um clássico que perdurou no tempo histórico é balizar os meios pelos quais a obra se tornou clássica, transformando Furtado em intérprete do Brasil, e fez as gerações posteriores signatários do economista paraibano.

Celso Furtado e os 60 anos de Formação econômica do Brasil é resultado de evento homônimo do referido livro - ambos organizados pelos pesquisadores Alexandre Macchione Saes e Alexandre de Freitas Barbosa, iniciativa da Biblioteca Brasiliana Guita e José Mindlin e do Instituto de Estudos Brasileiros da Universidade de São Paulo (IEB/USP) - realizado em novembro de 2019 no Centro de Pesquisa e Formação do Sesc, em São Paulo. Um fato especial circundou todo o evento e as instituições envolvidas, representado na participação de Rosa Freire d'Aguiar, que divulgou que o acervo pessoal de Celso Furtado passaria à guarda do IEB, como de fato ocorreu ainda em 20I9. Portanto, novas perspectivas se abrem com a pesquisa no arquivo e biblioteca de Furtado.

O impacto dessa possibilidade de pesquisa pode ser observado no trabalho de Elisabete Marin Ribas, intitulado "O arquivo pessoal de Celso Furtado: relações e relacionamentos para além dos bastidores da história econômica”, a respeito da transferência do arquivo pessoal de Furtado para o IEB, ao dizer sobre a importância desses arquivos: "Eles são mais um recurso de inspiração e orientação para nós que, seja organizando-os seja consultando-os, somos convidados a repensar nosso país e 're-sonhar' um futuro que cabe a nós construirmos" (p. 458).

Os 60 anos tinham outros dois ingredientes que favoreciam o ambiente e a 
convergência de disposições para o diálogo em torno de $F E B^{2}$ : por ser realizado no final de 20I9, o evento traçou algumas linhas argumentativas para o centenário de nascimento de Furtado, em 2020, data vindoura naquele momento e aguardada com muita expectativa, e que não foi frustrada pela pandemia, rememorada em forma de publicações, seminários, palestras e dossiês sobre o centenário; por fim, junto à realização do evento, d'Aguiar havia acabado de publicar Diários intermitentes I937-2002 (FURTADO, 20I9), livro que rapidamente se configurou em material de grande importância sobre Furtado, composto de escritos pessoais ainda não conhecidos pelos pesquisadores e que permeou diversos momentos do evento com elucidativas passagens quase como que "reveladas" pela leitura de Alexandre Freitas Barbosa diante do ineditismo da publicação naquele momento, com poucas semanas à disposição do público.

Os 50 anos de FEB em 2009 já haviam sido significativos para os pesquisadores e interessados na obra, principalmente com a publicação da edição comemorativa de FEB (FURTADO, 2009) por Rosa Freire d'Aguiar, que contém uma fortuna crítica de 2I trabalhos de brasileiros e estrangeiros por ela selecionados, que se tornou referência obrigatória para os pesquisadores de 2019 que participaram do livro resenhado.

O caminho foi buscar eixos em comum que perpassaram as análises sobre os 60 anos de FEB, em suas diversas medidas, recepções e interesses sobre a obra. Há perspectivas em múltiplas direções, desde a presença de $F E B$ na trajetória acadêmica dos pesquisadores, com gerações sendo formadas pela obra, ou enquanto problema de agenda de pesquisa, ou os significados dessa obra na forma do projeto político furtadiano, sendo possíveis mediações que permitem avaliar a extensão da obra e, principalmente, das suas ideias. Nessa direção, André Botelho, em "Um certo 'ar de família': formação, inserção, linhagens, sequências”, acena para o desafio de "pensar as ideias como forças sociais reflexivas" ao tratar "as ideias não apenas como produtos sociais, mas também, reflexivamente, produtoras do social” (p. 35).

Tomando de empréstimo o desafio de André Botelho, alguns pontos em comum foram identificados nos trabalhos que compõem o livro, entre outros que são possíveis: a recepção (imediata e ao longo dos 60 anos) e suas gerações de furtadianos; o método; as influências sobre FEB; a política; os usos possíveis de FEB 60 anos depois. Esses pontos foram selecionados em aproximação (flexível) com as seis partes do livro: I. FEB e o gênero de "formação"; II. Da economia brasileira para a história econômica: os debates historiográficos herdados de FEB; III. Teoria e método em FEB; IV. Da história econômica para a economia brasileira: o projeto político de FEB; V. A atualidade de FEB; VI. $\mathrm{O}$ arquivo de Celso Furtado no Instituto de Estudos Brasileiros.

A recepção de $F E B$ como obra de história econômica e de flagrante atualidade, em sua dinâmica de intervenção na realidade, rapidamente atingiu extensão nos meios universitário e acadêmico assim como na luta política. Saes e Rômulo Manzatto realizaram, no artigo "Os 60 anos de Formação Econômica do Brasil: pensamento, história e historiografia”, importante sistematização a partir da pergunta sobre

2 A partir de agora será adotado o acrônimo FEB para a obra Formação econômica do Brasil, apesar de Rosa Freire d'Aguiar nos relatar, no evento que resultou no livro resenhado, que "FEB", na vida privada com Furtado, se referia à Força Expedicionária Brasileira, à qual ele pertenceu como combatente na Segunda Guerra Mundial. 
como "diferentes gerações leram e debateram" $F E B$, apontando uma periodização ao longo das décadas. Entre os anos de I959 e I970, FEB teve "rápida disseminação", com três edições até I960, traduções para sete idiomas (até I975), e ampla repercussão mediante seus críticos; os trabalhos de Fernando Novais (I96I) e de Iglesias (I963) 3 são apontados como aqueles que "parecem extrair os elementos centrais nas interpretações posteriores" (p. 84). A década de I970 representa o momento em que FEB se torna um "cânone", ao mesmo tempo que se torna "um roteiro básico para cursos de história econômica do Brasil", referência nacional e internacional. $\mathrm{Na}$ década de I980, seguindo Chico de Oliveira (2003) em A navegação venturosa, FEB estava relegada somente aos cursos de história econômica, como algo do passado, aparentemente não mais disputando o presente. A década de I990 demonstra sua retomada na construção nacional, chegando ao século XXI com novo vigor para a ideia de desenvolvimento, a partir de elementos como a eleição de Luiz Inácio Lula da Silva, a indicação para o Nobel de economia (2003) e a criação do Centro Internacional Celso Furtado de Políticas para o Desenvolvimento (2005).

As gerações de furtadianos nesses 60 anos, leitores de $F E B$, enquanto recepção e trajetória da própria obra, formaram escolas, aglutinando linhas de interpretação sobre FEB que vigoraram por décadas. Chico de Oliveira é, sem dúvida, a grande ausência entre os furtadianos - no evento e no pensamento social brasileiro principalmente -, sendo figura que inspira uma chave de leitura para FEB das mais significativas e, talvez, de maior presença nas análises realizadas pelos pesquisadores nos 60 anos. O Centro Brasileiro de Análise e Planejamento (Cebrap), com a célebre publicação de A economia brasileira: crítica à razão dualista (OLIVEIRA, I972), e o Instituto de Economia da Universidade Estadual de Campinas (Unicamp), com seus "autores pós-furtadianos", como aponta Barbosa no artigo "Formação Econômica do Brasil, sessenta anos depois", “deram continuidade ao legado de Furtado" (p. 4I8), com intelectuais como Maria da Conceição Tavares, João Manuel Cardoso de Mello, José Serra, Guido Mantega, entre outros. Já Fernando Rugitsky, em "Luta de classes inibida? Furtado e a especificidade da estrutura social brasileira", fala dos "jovens furtadianos de esquerda", como Chico de Oliveira e Paul Singer (p. 334).

Toda efeméride como essa, de uma obra clássica do pensamento brasileiro, passa necessariamente pelo balanço de interpretação, um "teste" histórico, critérios alinhavados, nesse caso, ao acúmulo acadêmico e científico da "Nova Historiografia Econômica Brasileira”, (p. I64), conforme relata Saes em “Formação Econômica do Brasil e a Nova Historiografia Econômica Brasileira”.

Em "Formação Econômica do Brasil: Celso Furtado como historiador econômico", Flávio Rabelo Versiani se pergunta como a "estrutura de análise" foi afetada pelos avanços da história econômica (p. I22), assim como Flávio Saes aponta as "correntes críticas" e realiza um "balanço do estado atual das polêmicas interpretativas (p. I63). Versiani assinala várias passagens de FEB que, do ponto de vista historiográfico, sofreram forte crítica da literatura especializada, como a ideia de um papel passivo dos produtores de açúcar em relação aos comerciantes, ou as diferenças postas em

3 Rosa Freire d'Aguiar, no "Prefácio", afirma que, "aos olhos de Furtado", Iglesias foi quem melhor capturou "a noção de 'esboço" (p. ז3). 
FEB de protagonismo dos produtores do café em detrimento da acepção de rentistas ociosos para os produtores de açúcar. O capítulo I5 de $F E B$, "Regressão econômica e expansão da área de subsistência”, sobre a desagregação da economia mineira e a ideia de estagnação das primeiras décadas do século XIX, segundo Versiani e Saes, resultou em ampla revisão crítica4.

A pergunta a respeito do método utilizado em $F E B$ é capilar entre as análises dos 60 anos, já que a não explicitação do método histórico-estrutural por Furtado, como em um capítulo metodológico, é característica, talvez, desse gênero de formação, ou também segue a constatação de Fonseca de que os "clássicos' do estruturalismo latino-americano não nos deixaram estudos que detalhassem o método que embasa sua visão teórica” (p. 226). Vários autores se empenharam em trazer à luz algum aspecto do método de Furtado e da metodologia aplicada em FEB.

Fonseca (p. 232) remonta à obra de Furtado (I967) Teoria e política do desenvolvimento econômico a fim de analisar o Anexo Metodológico do capítulo 6, e aponta para o método estruturalista de Furtado de "dinamizar os parâmetros" dos modelos econômicos a fim de considerar os "fatores não econômicos". Em "Os usos da história em Formação econômica do Brasil", Roberto Pereira Silva direciona para as especificidades dos "usos" da história em FEB exatamente pelas inovações metodológicas que essa obra traz, distintas da tese de doutorado de Furtado ([I948] 200I) e A economia brasileira (I954), obras que foram pontos de partida para FEB, além de serem retomadas textualmente em determinados momentos de $F E B^{5}$.

Silva aponta, no artigo "Os usos da história em Formação econômica do Brasil", que a forma como a colonização é tratada através da dialética interno/externo, no impacto produzido em ambos os espaços (da história europeia e do espaço americano), bem como as interações entre os dois sistemas, a economia açucareira e a pecuária, apresentadas de forma estrutural (de curto e longo prazo) em uma "perspectiva dinâmica" são apostas metodológicas "consideravelmente diversas neste trabalho de I959”. Nesta direção, Maurício Coutinho, em "Formação econômica do Brasil: economia e história", afirma que "uma das características mais marcantes" de FEB foi a "aplicação de modelos econômicos à história" (p. 237). Pedro Paulo Zahluth Bastos, em "Modelo analítico e projeto político de Formação econômica do Brasil de Celso Furtado", sintetiza a percepção sobre o método: “Este talvez seja o principal significado do método histórico-estrutural: a estrutura tem história, e a história é periodizada pelas mudanças de estrutura" (p. 299).

As influências que atuaram sobre $F E B$ foram captadas em rumos diversos: a trajetória de Furtado no estruturalismo cepalino de base keynesiana seguramente é a influência mais significativa sobre $F E B$ que, para Bastos, ressoa na influência de Prebisch sobre Furtado, e a rejeição de ambos ao "individualismo metodológico

4 Como as noções de "arcaísmo como projeto", observando as relações internas na formação econômica nacional, de Fragoso e Florentino, os estudos de Stuart Schwartz sobre escravidão na Bahia, e as pesquisas sobre a economia mineira de Alcir Lenharo e Roberto Borges Martins.

5 Silva (p. 265) inclusive distingue as "preocupações metodológicas" dos trabalhos de 1948 e I954, que os tornam, "menos que complementares", distintos; a tese de doutorado de 1948 traz os "determinantes sociais e políticos da expansão marítima”, enquanto, no trabalho de I954, a "construção de modelos" econômicos sobressai. 
típico da economia neoclássica" e ao "nacionalismo metodológico", já que "a unidade de análise da perspectiva estrutural cepalina não é a nação, mas o sistema supranacional” (p. 298). A presença dos intérpretes do Brasil também instiga profundamente os pesquisadores, desde a paradoxal ausência de Caio Prado Jr., "a referência inexistente", como foi lembrado por d'Aguiar no "Prefácio" (p. II), omitido junto a outras referências da "bibliografia histórica brasileira", até a presença de Roberto Simonsen, e as sombras de Gilberto Freyre, entre outros. A redação de FEB em Cambridge, no período de I957 e I958, traz também as leituras principalmente dos keynesianos, como Furtado (2019) atesta em seus Diários intermitentes I937-2002: "Cambridge, I7.5.58. Tenho vontade de escrever um trabalho maior sobre o desenvolvimento recente (os últimos dez anos) da 'dinâmica econômica', principalmente as contribuições de Harrod, Joan Robinson e Kaldor”.

A ponte entre a interpretação histórica do subdesenvolvimento e a construção política do futuro aparece com centralidade entre os pesquisadores e o próprio campo acadêmico das ciências sociais e humanas, que reconhecem diante do atual esvaziamento do espírito da formação também os óbices da disputa pública e da coletividade pelos projetos políticos nacionais. Essa ponte é o verdadeiro elemento aglutinador dos trabalhos realizados sobre FEB, tratando-se de uma intersecção entre interpretação e diagnóstico que aponta "uma agenda ampla de investigação sobre os problemas nacionais" (p. 63), na expressão de Vera Alves Cepêda em "História, economia e projeto político em Formação Econômica do Brasil", uma "narrativa" que legitima "intervenções políticas sobre estruturas [...] para concentrar poder, pela argumentação racional, para agir" (p. 300), segundo Bastos, "um vaivém permanente entre impossibilidades do passado, incompletudes do presente e potencialidades do futuro" (p. 4IO) na definição de Barbosa. Nas palavras de Gilberto Bercovici, em "A dimensão de futuro em Formação econômica do Brasil", há algo prospectivo em FEB, "no qual o Estado era o agente do projeto de construção nacional" (p. 395).

Os desafios postos ao futuro dos furtadianos e, do mesmo modo, a permanência futura do pensamento de Furtado passam pela desconstrução das intervenções políticas planejadas e do desfalecimento das utopias de construção nacional. Se o método histórico-estrutural de interações dinâmicas de natureza histórica e econômica, aplicado às estruturas sociais e políticas, ainda forma parte de um horizonte político, será pela diferenciação dessa unidade - entre o método de Furtado e as incursões dos furtadianos na construção política nacional - que se poderá, primeiro, diagnosticar o tempo presente, nas novas perspectivas do subdesenvolvimento, para em seguida constatar a força do projeto político de base furtadiana, democrático, republicano, de enfrentamento das desigualdades, pela transformação estrutural. A luta é por não ser o novo "bonde perdido" do desenvolvimento, na expressão de Fernanda Graziella Cardoso utilizada em "O bonde perdido do desenvolvimento: complexidade econômica e a atualidade de Formação Econômica do Brasil". É importante identificar como o "horizonte de expectativas" construído em FEB "vai atingindo um tom mais amargo" (p. 36I), da construção interrompida, segundo Carlos Alberto Cordovano Vieira, em "Sessenta anos de Formação econômica do Brasil: da pré-revolução brasileira à construção interrompida”. Se as ideias têm força reflexiva sobre o social, parece que o desafio de Furtado ao 
escrever FEB, nas palavras de Cepêda, deve ser redimensionado no presente, na necessária combinação entre análise histórica e diagnóstico, ao afirmar sobre as estratégias utilizadas por Furtado em FEB: "observa as possibilidades e os limites que se abrem para uma possível superação do subdesenvolvimento” (p. 56).

\section{SOBRE O AUTOR}

GUSTAVO LOUIS HENRIQUE PINTO é doutor em Ciência Política pela Universidade Federal de São Carlos (UFSCar) e professor do Instituto Federal de Educação, Ciência e Tecnologia de Goiás (IFG), campus Uruaçu. gustavo.pinto@ifg.edu.br https://orcid.org/o0o0-0002-I832-2038

\section{REFERÊNCIAS}

FURTADO, Celso. A economia brasileira: contribuição à análise do seu desenvolvimento. Rio de Janeiro: A Noite, I954.

FURTADO, Celso. Teoria e política do desenvolvimento econômico. São Paulo: Editora Nacional, I967.

FURTADO, Celso. (I948). Economia colonial no Brasil nos séculos XVI XVII. São Paulo: Hucitec/ABPHE, $200 I$. FURTADO, Celso. Formação econômica do Brasil: edição comemorativa - 50 anos. Organização de Rosa Freire d'Aguiar Furtado. São Paulo: Companhia das Letras, 2009.

FURTADO, Celso. Diários intermitentes: 1937-2002. Organização, apresentação e notas de Rosa Freire D’Aguiar. Prefácio de João Antonio de Paula. São Paulo: Companhia das Letras, 2019. OLIVEIRA, Francisco de. A economia brasileira: crítica à razão dualista. Petrópolis: Vozes, I972. OLIVEIRA, Francisco de. A navegação venturosa: ensaios sobre Celso Furtado. São Paulo: Boitempo, 2003. 